\title{
Safeguarding marine life: conservation of biodiversity and ecosystems
}

Delphi Ward ${ }^{1,2}$, Jess Melbourne-Thomas ${ }^{2,3}$, Gretta T Pecl ${ }^{1,2}$, Karen Evans ${ }^{3}$, Madeline Green $^{2,3}$, Phillipa C Mccormack ${ }^{2,4}$, Camilla Novaglio ${ }^{1,2,3}$, Rowan Trebilco ${ }^{2,3}$, Narissa Bax ${ }^{1,2}$, Madeleine J Brasier ${ }^{1}$, Emma L Cavan ${ }^{5}$, Graham Edgar ${ }^{1}$, Heather Hunt ${ }^{6}$, Jan Jansen ${ }^{1}$, Russ Jones $^{7,8}$, Mary-Anne Lea ${ }^{1,2}$, Reuben Makomere ${ }^{4}$, Chris Mull ${ }^{9}$, Jayson M Semmens ${ }^{1}$, Janette Shaw ${ }^{1,2}$, Dugald Tinch ${ }^{10}$, Tatiana J Van Steveninck ${ }^{3,11}$, and Cayne Layton ${ }^{1,2}$

${ }^{1}$ Institute for Marine and Antarctic Studies, University of Tasmania

${ }^{2}$ Centre for Marine Socio-ecology, University of Tasmania

${ }^{3}$ CSIRO Oceans and Atmosphere

${ }^{4}$ School of Law, University of Tasmania

${ }^{5}$ Department of Life Sciences, Silwood Park Campus, Imperial College London

${ }^{6}$ Department of Biological Sciences, University of New Brunswick

${ }^{7}$ Hereditary Chief

${ }^{8}$ Haida Nation, PO Box 1451, Skidegate, B.C. Canada V0T 1S1

${ }^{9}$ Department of Biology, Dalhousie University, Halifax, NS, B3H 4R2, Canada

${ }^{10}$ Tasmanian School of Business \& Economics, University of Tasmania, Hobart, TAS 7001, Australia

${ }^{11}$ Leiden University

November 11, 2020

\section{Hosted file}

Ward_et_al_Safeguarding_marine_life_conservation_of_ecosystems_and_biodiversity.pdf available at https://authorea.com/users/364319/articles/491405-safeguarding-marine-lifeconservation-of-biodiversity-and-ecosystems 